\title{
RELATO DE EXPERIÊNCIA: INCLUSÃO DIGITAL DE IDOSOS FREQUENTADORES DE UM CENTRO-DIA NO DISTRITO LISBOA - PORTUGAL
}

\author{
Marcia Sales \\ Universidade Fedral de santa Catarina \\ maciabarross@gmail.com \\ Marilia Amaral \\ Universidade Tecnológica Federal do Paraná \\ marilia.utfpr@gmail.com \\ André Barros de Sales \\ Universidade de Brasília \\ andrebdes@gmail.com \\ Bruna Rodolfo Mazzali \\ Universidade Federal de Santa Catarina \\ brumazzali@hotmail.com \\ Rita Brito \\ Instituto de Educação, Universidade de Lisboa \\ britorita@campus.ul.pt
}

\begin{abstract}
Resumo
Esta investigação resulta da experiência de inclusão digital realizada na cidade de Lisboa, Portugal, com um grupo de idosos que frequentam o Centro-dia. Participaram neste estudo 20 idosos, com idades compreendidas entre os 60 a 80 anos de idade, todos alfabetizados. Foram oferecidas oficinas de informática básica, com cinco encontros semanais de três horas durante um mês. Como instrumento de coleta de dados foram utilizados questionários. Entre os resultados encontrados pela equipe de pesquisa, ressalvam-se as suas preferências pelas Tecnologias de Informação e Comunicação, nomeadamente a Web, com destaque para as pesquisas online e a utilização o correio eletrónico. Foram igualmente constatadas dificuldades desses grupo de idosos em interagir com ferramentas de bate-papo.
\end{abstract}

Palavras-chave: Tecnologias de Informação e Comunicação, idosos, computador, web.

\section{REPORTING A STUDY: ELDERLY DIGITAL INCLUSION OF A GROUP OF DAYCARE SENIORS IN LISBON DISTRICT - PORTUGAL}

\begin{abstract}
This research results from a digital inclusion experience held in Lisbon, Portugal, with a group of seniors who attend the adult daycare center-day. The sample consisted of 20 seniors, aged 60-80 years old, all literate. Basic computer workshops were offered with five weekly meetings of three hours for a month. As data collection instruments questionnaires were used. Among the findings of the research team, it was checked their preferences on Information and Communications Technologies, specially the web,
\end{abstract}


including research on the web and to use the e-mail. It was also found difficulty of the elderly group to interact with chat tools.

Keywords: Information and Communications Technology, elderly, computer, Internet.

\section{INTRODUÇÃO}

Desde o início do século que se denotam transformações demográficas, verificando-se uma população cada vez mais envelhecida. Uma antevisão do envelhecimento prevê que os cidadãos com mais de $65 \operatorname{anos}^{1}$, entre os anos de 2004 e 2050, chegarão aos 58 milhões, o que equivalerá a $77 \%$ do total da população atual da união européia (Malanowski, Özcivelek \& Cabrera, 2008). Este é um efeito de desenvolvimentos científicos e técnicos, alterações econômicas e valorização da importância da educação, higiene e saúde pública.

Uma série de inovações tecnológicas transbordam quase que diariamente na sociedade, podendo estar relacionadas a hardware, software ou aplicativos de várias marcas, modelos e funções. Tais tecnologias podem ofertar aos idosos um modo mais confortável e econômico de realizar tarefas diárias e banais, como consultar portais do governo, acessar ao banco (e-banking), fazer compras (e-shopping), apoio assistido em casa (i.e. medição da tensão), maior disponibilidade para apoio ao longo da vida (lifelong learning) e reabilitação através de meios computadorizados.

Outras vantagens da utilização de tecnologias por idosos, nomeadamente o computador, prendem-se com o fato de caso participem continuadamente em cursos de informática, irão verificar-se melhorias das atitudes e aprendizagem destes (Morris, 1992), melhoria das competências relativas à autonomia, comunicação (Chaffin \& Harlow, 2005) e prevenção do declínio cognitivo (Wasserman et al., 2012). Esta utilização permite-lhes também a conexão com familiares e amigos, assistência relativa a assuntos relacionados com saúde, irão permanecer funcionalmente independentes e a sua auto-estima melhorará (Jones \& Bayen, 1998; Purdie \& Boulton-Lewis, 2003; Rogers et al., 2004, Sales, 2002; Sales, 2007).

Tendo sido constatada a importância da utilização das TIC por idosos e a sua vontade em querer utilizá-las, foi desenvolvido este estudo de modo a podermo-nos focalizar nas práticas de TIC destas pessoas. Ao longo do texto, a palavra idoso terá o significado de pessoas com mais de 65 anos de idade.

Diante do exposto, as perguntas de pesquisa que nortearam essa investigação foram: Que utilizações fazem os idosos do computador e da web? Quais as suas opiniões sobre estas tecnologias? Os objetivos do estudo foram: (i) averiguar as opiniões dos idosos relativamente ao computador e à web, (ii) verificar quais as suas dificuldades na utilização destes, e (iii) quais as suas práticas no computador.

Para tanto, o estudo está dividido em cinco seções, começando por esta Introdução; na segunda seção, a metodologia e seus procedimentos; na terceira seção, apresentando-se os resultados e discussão. A quarta seção é dedicada às considerações finais com os

\footnotetext{
${ }^{1}$ Segundo a Organização das Nações Unidas (ONU, 1982), nos países desenvolvidos é considerado idoso a pessoa acima de 65 anos e nos países em desenvolvimento a partir de 60 .

2 Segundo a Associação dos Familiares e Amigos dos Idosos - Centro-Dia - "Caracteriza-se por ser um espaço para atender idosos que possuem limitações para a realização das Atividades Básicas de Vida Diária (ABVD), que vivem com suas famílias, porém, os familiares não dispõem de tempo integral para ficarem no domicílio junto com o idoso"
} 
resultados mais relevantes deste estudo e, por último, o rol das referências bibliográficas.

\section{REFERENCIAL TÉORICO}

Em Portugal a população idosa residente, com 65 anos ou mais, é de 2,023 milhões de pessoas, representando cerca de $19 \%$ do total da população. As regiões com os percentuais mais elevados são: Alentejo com 24,3\%, o Centro do país com 22,5\% de idosos e Lisboa tem um contingente de $18,4 \%$ de idosos, conforme o Instituto Nacional de Estatística (INE, 2015). Neste país o índice de envelhecimento é fornecido pela relação entre o número de idosos (população com 65 ou mais anos) e o número de jovens (população com 0-14 anos), indicado habitualmente pelo número de idosos por cada 100 jovens. Este índice em Portugal é de 129, o que significa que o país tem hoje mais população idosa do que jovem, (INE, 2015).

À medida que as pessoas envelhecem, sofrem algumas mudanças decorrentes da idade, que podem interferir em algumas habilidades, como por exemplo a capacidade de adaptar aos próprios problemas relacionados à idade. Quando essas mudanças envolvem o uso de tecnologia, algumas dessas podem afetar mais do que outras, tais como alterações na visão, audição e o tremor nas mãos, podem causar mais obstáculos para essa interação, em relação à pele enrugada (LINH, 2014; SALES, 2007) .

A utilização das TIC pelos usuários idosos, pode facilitar o acesso à informações sobre saúde, turismo, sites de relacionamento, correio eletrónico, mensagens instantâneas, conta bancária, fazer pesquisas, comprar pela web, etc. As tecnologias podem ser essenciais na vida das pessoas idosas, principalmente para aquelas com algum tipo de dificuldade de mobilidade, limitações físicas, motoras, cognitivas, auditivas e visuais, além da dependência de outras pessoas para realizar tarefas do dia a dia.

Nas afirmações de alguns pesquisadores (Conci, Pianesi, Zancanaro, 2009; Sales, 2007), ao envelhecer as pessoas podem enfrentar alterações de ordem sensorial (ex.: visão e audição), motora e cognitiva, que podem influenciar na aprendizagem, levando mais tempo para aprender novos conceitos. Esses autores reforçam a necessidade de criar abordagens didáticas diferenciadas para os idosos.

Para Czaja e Lee (2003) é crença comum de que os idosos são resistentes à mudança e não querem interagir com produtos de "alta tecnologia", como computadores. No entanto, a natureza de sua experiência com computadores, treinamento disponível, suporte, facilidade de acesso e o tipo de aplicações disponíveis são fatores determinantes para promover sua receptividade.

Um estudo realizado por Sales, et. al., (2014) executado na Universidade Federal de Santa Catarina, Florianópolis, Brasil, sobre a preferência de uso das Tecnologias de Informação e Comunicação (TIC) disponíveis na web, por um grupo de 51 idosos, com a média de idade de 67,78 anos, destacou a preferência desse grupo de idosos pelo uso do e-mail seguindo pelo uso de bate-papo.

Demunter, (2006) constatou que os idosos têm demonstrado interesse em utilizar as TIC, o que comprova um estudo realizado entre 2002 e 2007 entre a população idosa de cinco países da União Europeia, demonstrando que a utilização da Internet pelos idosos duplicou, tendo-se registado, em 2001, 27\% de utilizadores e em 2007 foram registados 44\% (Seniorwatch, 2008). Concordando com estes dados estão Hernández-Encuentra et.al (2009), onde entrevistaram um grupo de idosos que frequentou um curso online na Universitat Oberta de Catalunya, mencionando que querem estar ligados às TIC e adaptarem-se às mesmas, de modo a poderem participar na sociedade da informação.

De facto, vivemos na sociedade da informação e as tecnologias cercam-nos, quer na área da saúde, de educação, e nos serviços diários do dia a dia. Os idosos não se querem 
sentir excluídos nem à margem da sociedade e por isso mostram vontade em utilizar as tecnologias (Wasserman et al., 2012).

\section{METODOLOGIA}

\subsection{Abordagem de investigação}

Esta investigação segue uma abordagem metodológica de natureza quantitativa e qualitativa, centrando-se na averiguação das opiniões da amostra sobre as suas práticas na utilização do computador.

\subsection{Participantes}

A amostra participante deste estudo é constituída por um grupo de 20 idosos residentes no distrito de Lisboa, Portugal. Durante um mês os idosos utilizaram às instalações de uma instituição pública - Centro-Dia ${ }^{2}$, que possuía computadores desktop conectados à Internet. Alguns desses idosos já tinham algum contato com as TIC pois já possuíam computador e traziam-no para estas práticas, no entanto outros nunca o tinham utilizado.

Estas práticas não poderão ser apelidadas de curso de informática ou formação, pois o objetivo não foi transmitir competências específicas sobre o computador ou aprofundar qualquer tema relacionado com informática, não existindo também qualquer tipo de programa estabelecido, mas sim proporcionar aos idosos o contacto com esta ferramenta e apresentar-lhes algumas das suas potencialidades. No entanto, e de modo a podermonos referir a estas, iremos apelidá-las de oficinas de informática básica.

Assim, estas oficinas realizaram-se ao longo um mês, cinco vezes por semana, das 14 horas às 17 horas, perfazendo um total de 60 horas de oficinas num mês. Durante estas oficinas estavam sempre estavam presentes dois adultos de modo a poder esclarecer dúvidas dos idosos participantes. Todos os idosos participantes demonstraram interesse particular por aprender a utilizar as ferramentas e recursos tecnológicos disponibilizados pelo computador e a web.

Dos 20 inquiridos, sete eram homens e 13 eram mulheres, com classe social heterogênea. Desses, seis idosos (30\%) tinham entre 70-75 anos de idade, seguindo com cinco idosos (25\%) com idade entre os 60-65 anos. Seis idosos (30\%) tinham cursado $1 .^{\circ}$ ciclo (1..$^{\circ}$ ano ao $4 .^{\circ}$ ano); cinco idosos $(25 \%) 2 .^{\circ}$ ciclo $\left(5 .^{\circ}\right.$ e $6 .^{\circ}$ ano); quatro idosos $(20 \%)$ cursaram o $3 .^{\circ}$ ciclo $\left(7 .^{\circ}\right.$ ao $9 .^{\circ}$ ano); quatro idosos (20\%) cursaram o secundário; e um idoso cursou licenciatura.

\subsection{Procedimentos de coleta de dados}

Os objetivos deste estudo foram apresentados aos idosos participantes nas oficinas e estes foram questionados se gostariam de participar no estudo, ao qual todos acederam com muito agrado. Foi-lhes enviado um questionário para o seu correio eletrônico pessoal, incluindo uma breve descrição sobre o intuito e objetivos do estudo, assim como a confirmação da confidencialidade dos dados proporcionados. O questionário foi preenchido online por todos os idosos com relativa facilidade.

\footnotetext{
${ }^{2}$ Segundo a Associação dos Familiares e Amigos dos Idosos - Centro-Dia - "Caracteriza-se por ser um espaço para atender idosos que possuem limitações para a realização das Atividades Básicas de Vida Diária (ABVD), que vivem com suas famílias, porém, os familiares não dispõem de tempo integral para ficarem no domicílio junto com o idoso" http://www.ciape.org.br/Centro_Dia_Idoso.pdf .Ou seja, os idosos permanecem no centro-dia apenas durante o dia, deslocando-se para as seus lares para pernoitar.
} 
Foi utilizado um questionário já validado em investigações anteriores, porém foi feita uma vasta pesquisa bibliográfica com o intuito de encontrar um instrumento que correspondesse aos objetivos do estudo. Foram encontrados dois estudos com objetivos semelhantes ao deste, onde também foram utilizados questionários (Gonçales, 2011; Pereira, 2010). Entrou-se em contacto com os autores solicitando uma cópia dos questionários utilizados e a sua autorização para os podermos aplicar à nossa amostra, os quais nos foram cedidos o uso. Após uma leitura cuidadosa dos questionários, foram selecionadas algumas questões de cada um dos questionários. Deste modo foi elaborado um novo questionário de coleta de dados que atendesse os objetivos da investigação proposta.

\subsection{Procedimentos de análise e sistematização dos dados}

O questionário utilizado era composto por 26 questões, estando estas organizadas em 3 partes: a parte A consistia na caracterização da amostra; com a parte B pretendeu-se averiguar quais os conhecimentos e que tipo de utilização fazem os idosos do computador; a parte $\mathrm{C}$ referia-se às aprendizagens relativas às oficinas de informática. Este questionário era composto por questões fechadas e abertas, sendo que as questões de resposta fechada tinham como base uma escala de Likert e foram alvo de uma análise estatística descritiva; relativamente às questões abertas, fez-se uma análise de conteúdo recorrendo-se à análise categorial, já que esta permite proceder à organização e classificação dos dados recolhidos, de forma a possibilitar a realização de inferências válidas para o contexto em questão (Bardin, 1977).

\section{RESULTADOS E DISCUSSÃO}

Os idosos inquiridos usam o computador em casa (64\%) e consideram a web um serviço relevante, pois 59\% utiliza-a. No entanto, uma parte da amostra $(27 \%)$ não utiliza o computador em casa, referindo principalmente dificuldades de âmbito financeiro. Todos os inquiridos que afirmaram não ter computador, gostariam de o ter e também de aceder à web no mesmo, revelando um grande interesse pela sua utilização. De fato, o computador continua a ser uma ferramenta dispendiosa para alguns idosos.

No computador, as atividades preferidas pelos idosos são pesquisar na web (85\%) e também realizar atividades de caráter social, nomeadamente enviar e receber correio eletrônico (70\%), e conversar com familiares e amigos no chat (55\%). Para além destas atividades, também realizam jogos (50\%), ouvem música ou assistem a programas e vídeo pela web (45\%), entre outras atividades que estão detalhadas no Gráfico 1: 


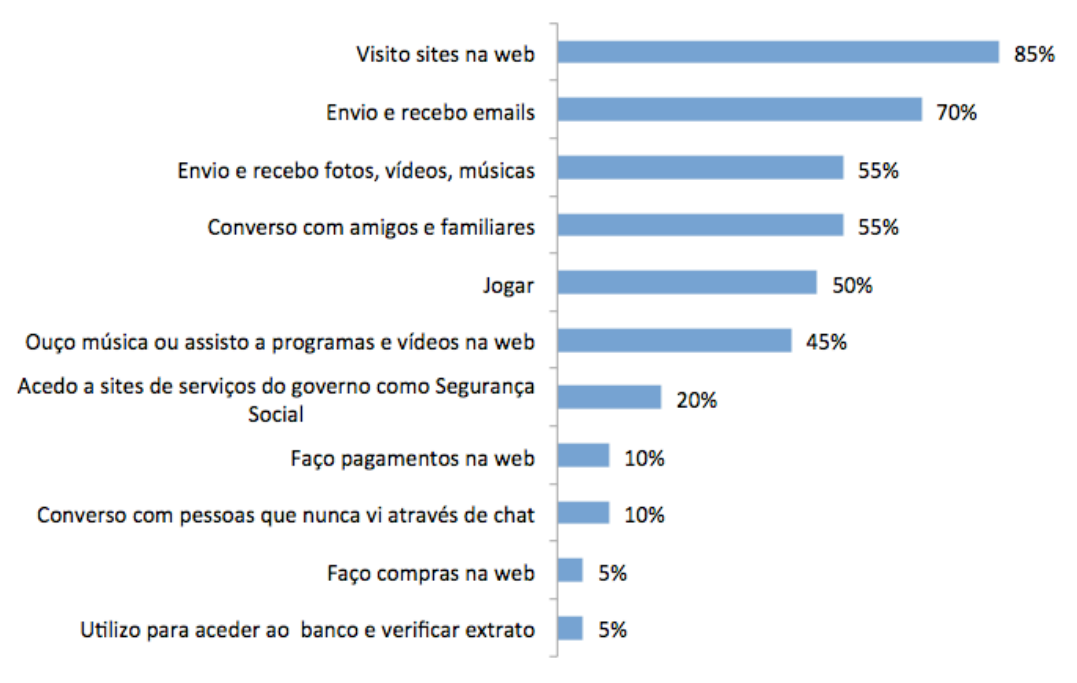

Gráfico 1: Atividades preferidas desse grupo de idosos no computador.

Considerando o âmbito da utilização da web, os idosos preferem usar aplicações onde possam socializar, como o envio de correio eletrônico (70\%), o Facebook (60\%) o Skype (40\%).

Questionados sobre o porquê de utilizar o Facebook, a maioria das respostas recai sobre "para falar com amigos e familiares". Efetivamente, a parte social é um fator muito importante na utilização do computador por idosos, permitindo-lhes a aproximação entre gerações, podendo prevenir o isolamento e agindo como um complemento de lazer.

O computador é uma ferramenta atrativa para os idosos, pois a maioria da amostra (64\%) refere que, independentemente das suas habilidades, adora utilizar o computador e a web e sentem-se medianamente preparados para aprender coisas novas sobre estes $(55 \%)$. No entanto, apesar de o utilizarem, não consideram o computador e a web uma ferramenta indispensável do seu dia-a-dia, sendo que apenas $36 \%$ o refere como sendo muito importante/útil.

São várias as ações que os idosos nomeiam como sendo capazes de fazer, relativas ao computador, nomeadamente aceder à web (95\%) ligar e desligar o computador (90\%), escrever um texto (85\%), fazer pesquisas na Internet (80\%), consultar e enviar correio eletrônico $(75 \%)$ entre outras referidas no Gráfico 2.

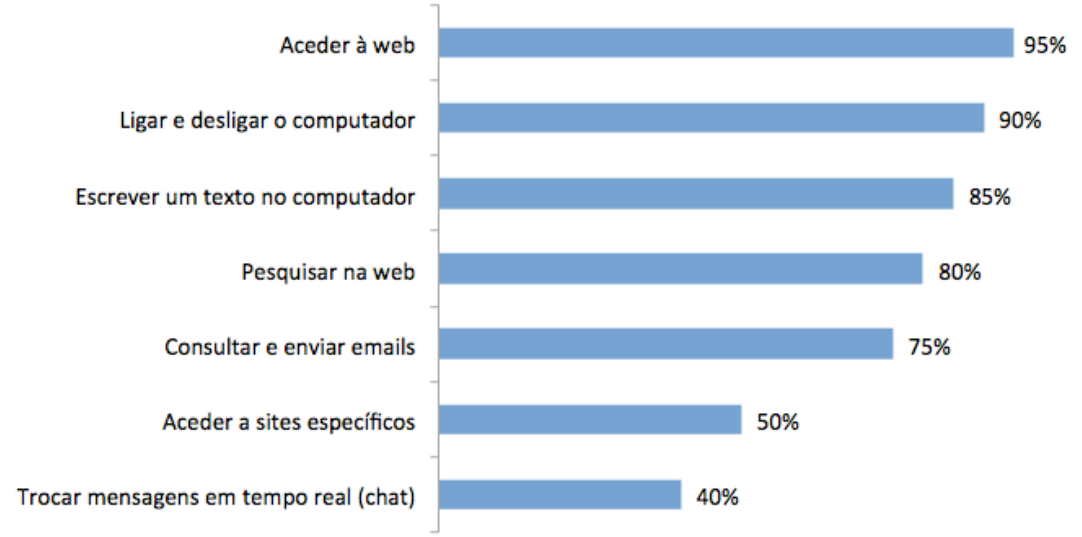

Gráfico 2: atividades realizadas no computador. 
Quando os idosos têm problemas relativos ao uso do computador ou web, recorrem principalmente a um amigo ou conhecido (serviço gratuito) $(40 \%)$ ou a um grupo como o que participaram nestas oficinas $(40 \%)$. Podemos verificar outras escolhas conforme apresentado no Gráfico 3.

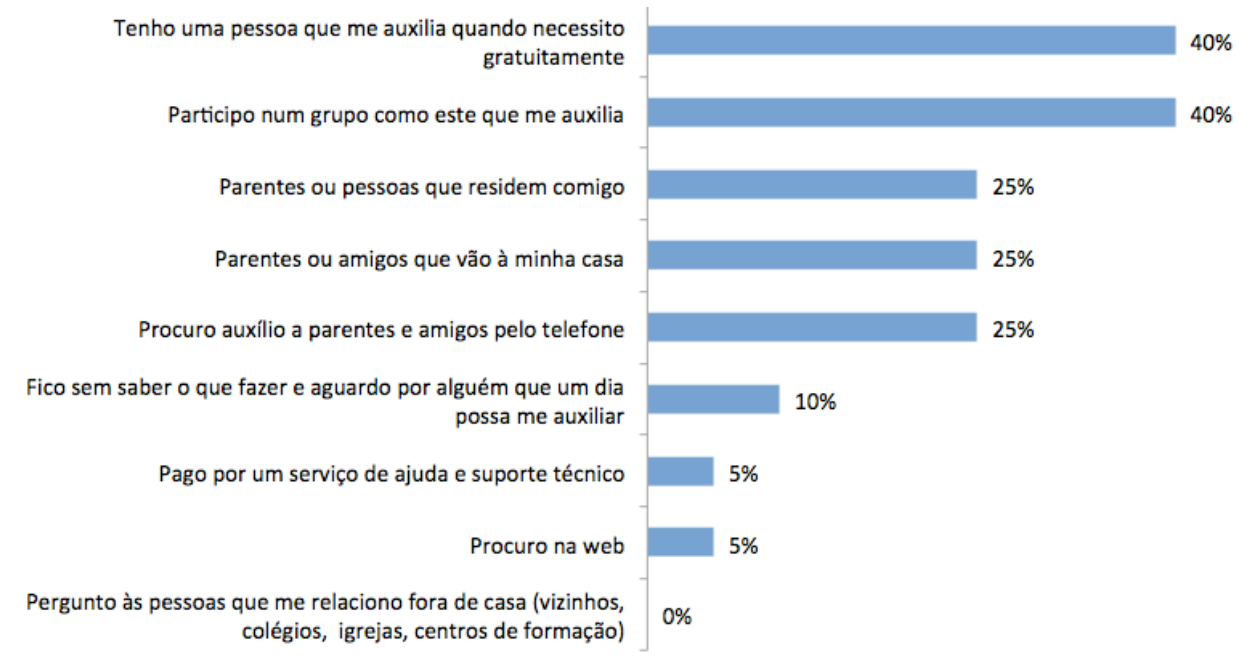

Gráfico 3: a quem os idosos recorrem quando têm problemas no uso computador ou Internet.

A web é um tema de interesse para os idosos, pois quando pessoas conhecidas conversam sobre esse tema, os idosos mostram-se interessados em participar na conversa com o objetivo de aprender, conforme podemos verificar no Gráfico 4.

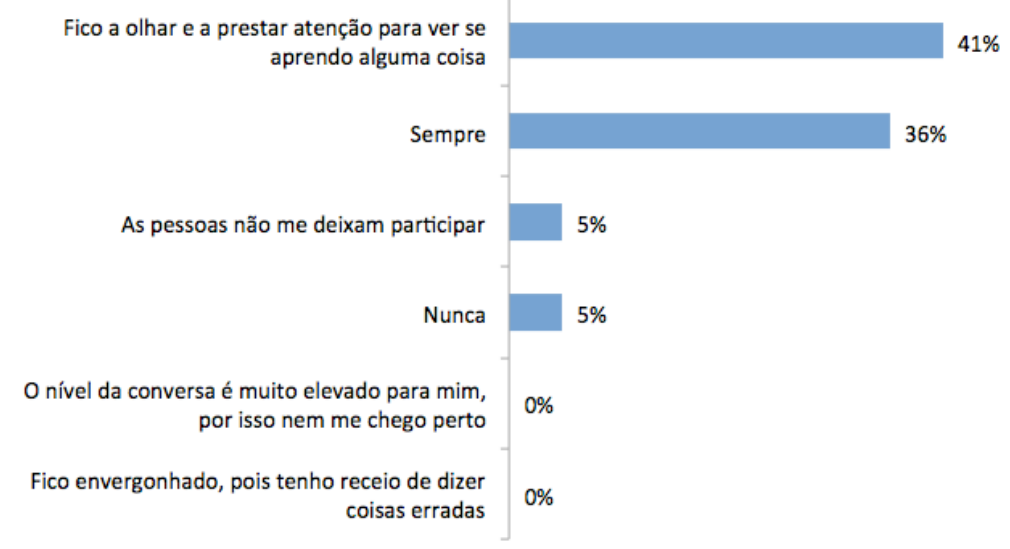

Gráfico 4: interesse em participar em conversas sobre Internet.

De modo a obterem novos conhecimentos sobre o computador e web, os idosos preferem majoritariamente conversar com pessoas que conhecem (60\%) ou inscreverem-se num curso (30\%).

O Gráfico 6 ilustra as atividades preferidas do grupo de idosos participantes do estudo. Ao longo destas oficinas foram elas: em $1^{\circ}$ lugar, fazer pesquisas na web, sendo que $55 \%$ refere agrado nesta atividade; em $2^{\circ}$ lugar a utilização do editor de texto, com $45 \%$ dos idosos a referir esta tarefa; em $3^{\circ}$ lugar o acesso ao correio eletrónico, referido por $32 \%$ dos participantes; por último, em $4^{\circ}$ lugar, a utilização das redes sociais, referido por $27 \%$ dos participantes. Tais dados são bem similares aos encontrados por Sales, et.al. (2014) em suas pesquisas de inclusão digital com pessoas idosas, realizada em 
Florianópolis, SC - Brasil assim como os encontrados por Wasserman et al. (2012), que referem que os idosos que participaram na sua pesquisa (27 participantes) gostavam de utilizar o Facebook por questões sociais e por ser uma plataforma de fácil utilização, tendo preferência pela utilização do chat e compartilhamento de fotos.

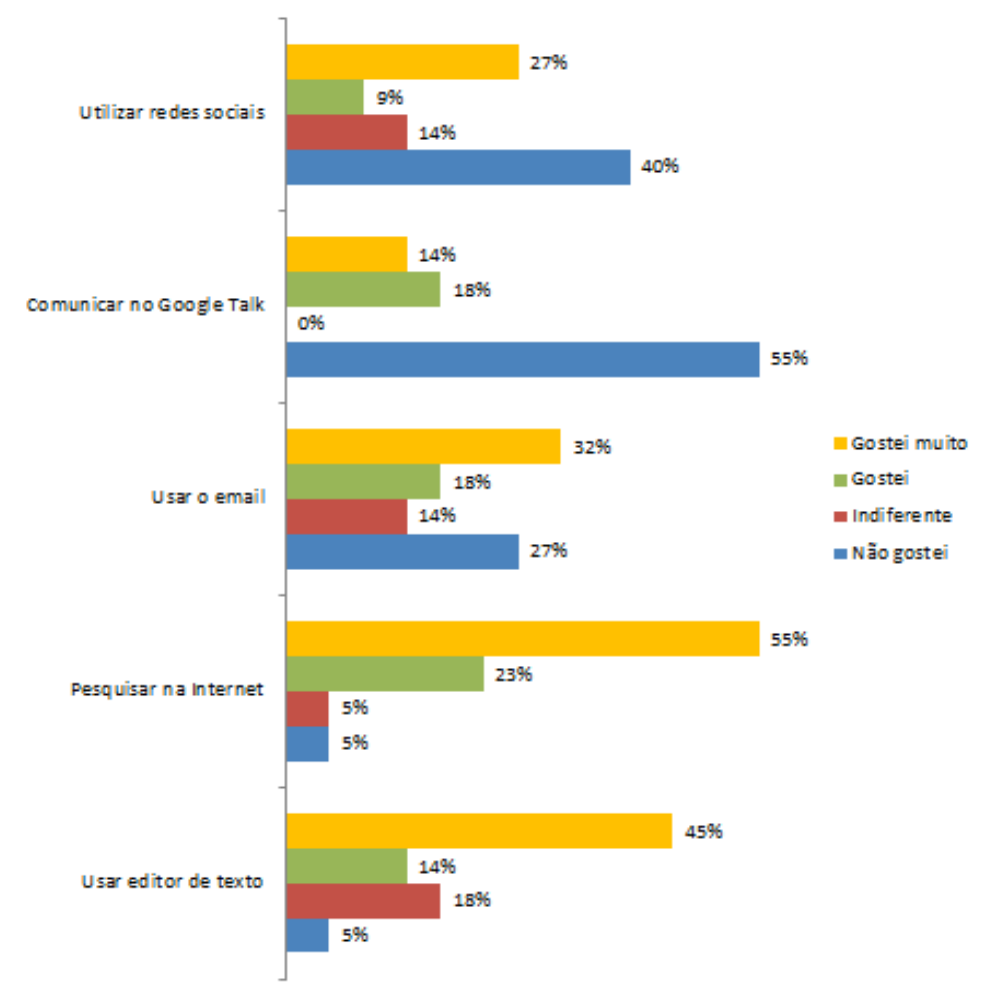

Gráfico 6: atividades que os idosos mais gostaram de realizar nas oficinas

Relativamente às tecnologias que os idosos tiveram muita dificuldade em utilizarem sozinhos para se comunicar, $50 \%$ refere a ferramenta de bate-papo. Um dos possíveis motivos talvez seja que a utilização não seja acessível para esta amostra. Com $32 \%$ ficaram as atividades de enviar correio eletrónico e abrir um anexo do email. Conjectura-se que nessas duas atividades o maior problema encontrado foi o excesso de informações expostas na tela, aumentando a densidade informacional e assim dificultando a condução do usuário em encontrar o botão para enviar mensagem. $\mathrm{O}$ Gráfico 7 a seguir expõe esses dados. 


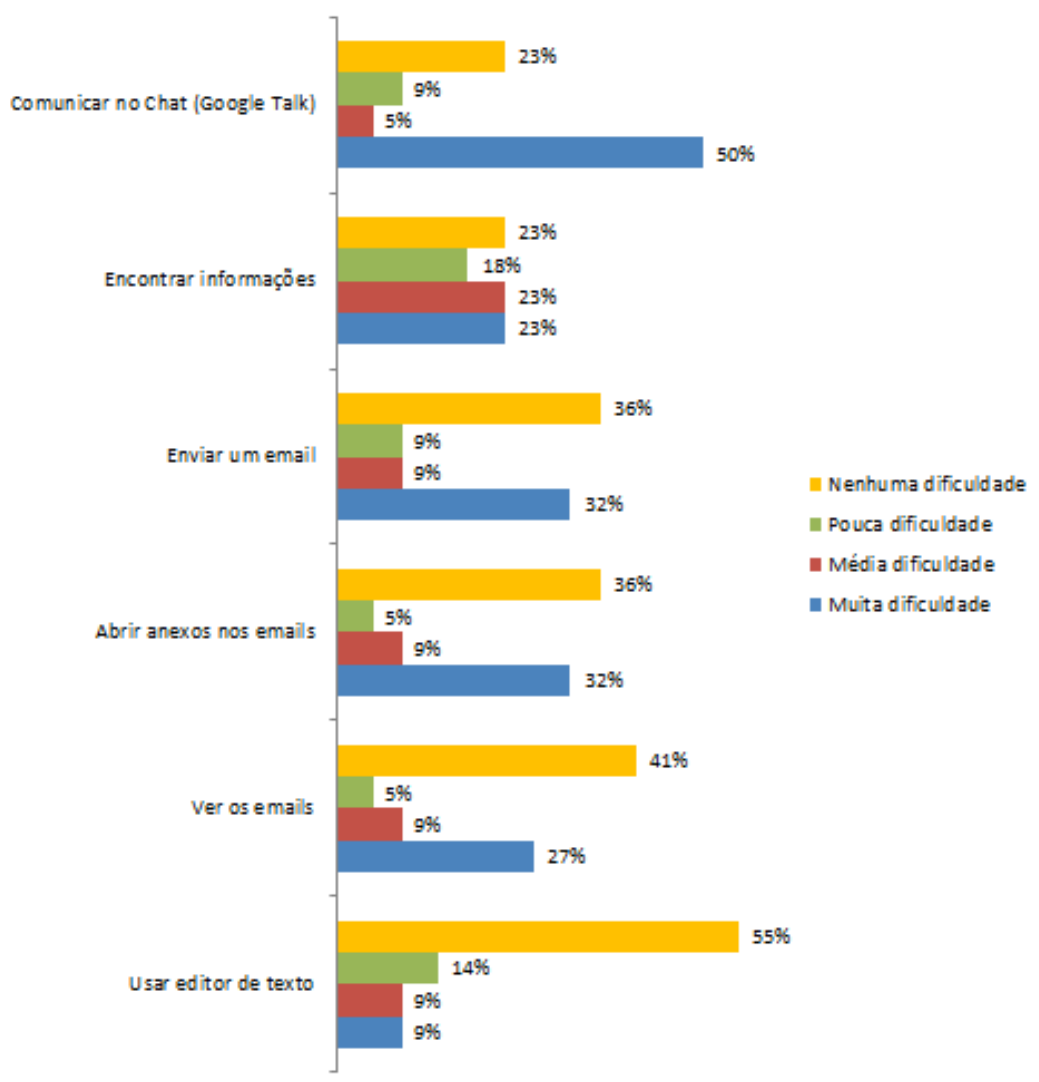

Gráfico 7: dificuldades que os idosos tiveram nas oficinas

Questionados sobre a experiência destas oficinas, 13 idosos (68\%) são da opinião que estas contribuíram para aumentar a satisfação e a qualidade do uso do computador, sendo que 12 idosos (59\%) reconhecem que seria importante obter mais formação para utilizar esta ferramenta com mais satisfação e qualidade e 17 idosos (86\%) consideram importante participar num grupo que proporcione este tipo de conhecimentos.

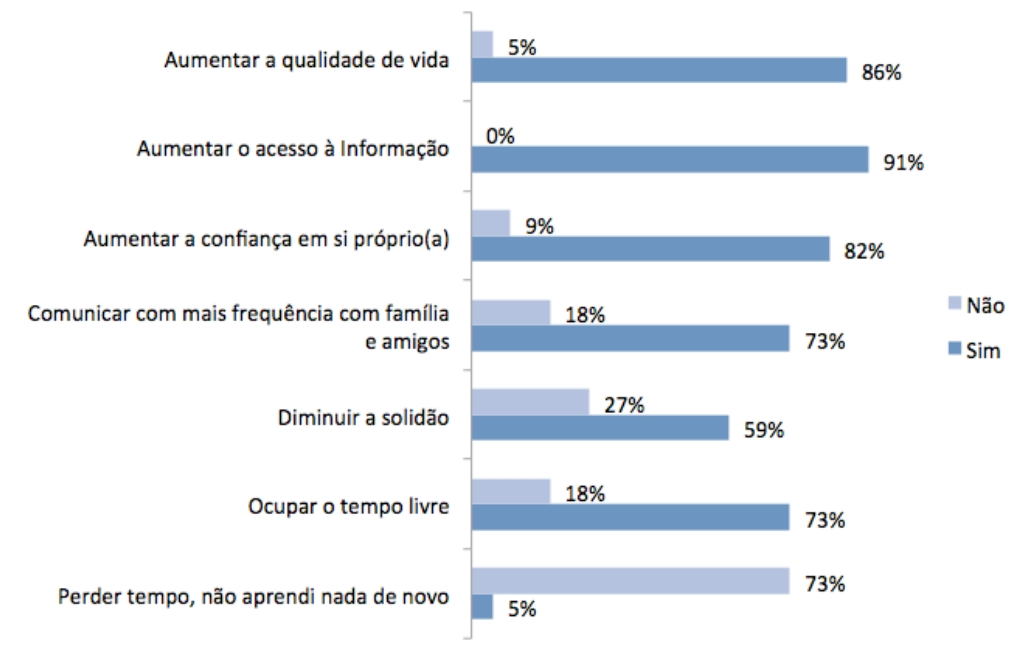

Gráfico 8: vantagens da utilização do computador

Entre os resultados encontrados sobre as vantagens das pessoas idosas utilizarem o computador, podem-se relacionar outros enfoques, tais como: 
a) de inclusão: 18 idosos (91\%) afirmaram que a utilização do computador permitiu ampliar o acesso à informação;

b) de autonomia: 16 idosos ( $82 \%$ ) aumentaram a confiança em si próprios;

c) de conhecimento: 14 idosos $(73 \%)$ disseram que conseguem comunicar-se com as ferramentas TIC com família e amigos;

d) de condição de vida: 17 idosos (86\%) aumentaram a qualidade de vida, 12 idosos (59\%) diminuíram a solidão e 14 idosos (73\%) disseram que ocupam o tempo livre.

\section{CONSIDERAÇÕES FINAIS}

Por meio dos dados recolhidos, foi verificado neste grupo de idosos o gosto em usar o computador e a web, embora admitam algumas dificuldades nesta utilização. Salienta-se o fato da preferência dos idosos por aplicações relacionadas com a parte social, o desejo de comunicarem e interagirem com amigos e familiares, trocarem informações, fotografias, episódios das suas vidas e incluírem-se socialmente.

No que concerne às oficinas, este grupo de idosos tiveram a opinião que estas oficinas permitiram que eles conhecessem melhor a utilização do computador e das suas ferramentas.

Dentre as contribuições deste artigo, destacam-se a preferências de uso das TIC, nomeadamente a web, por um grupo de 20 idosos respondentes da pesquisa. Eis os resultados: 17 idosos (85\%) apontaram que pesquisar na web é a atividade preferida quando estão a utilizar o computador; 14 idosos (70\%) gostam de utilizar o correio eletrónico; e 11 idosos (55\%) mencionaram que gostam de conversar com amigos e familiares utilizando o chat.

Entre as dificuldades encontradas por esse grupo ao utilizarem sozinhos o computador, $50 \%$ dos idosos queixaram-se da ferramenta de bate-papo; 32\% mencionaram os obstáculos encontrados para abrir anexos no correio eletrónico.

As atividades preferidas no correio eletrónico são ler e encaminhar mensagens com fotos, vídeos e músicas para os familiares, amigos e colegas. Já sobre o uso de rede social virtual, no grupo estudado, somente sete idosos (35\%) disseram que gostam de usar uma rede social, oito idosos (40\%) não gostam e três idosos (14\%) são indiferentes evidenciando um elevado índice de desinteresse em participar das redes sociais. Pode-se ventilar que uma das restrições desses grupos de idosos sobre o uso das redes sociais pode ser o fato da exposição pessoal.

Observou-se que a idade não é justificativa para a exclusão do mundo digital, muito pelo contrário, os idosos gostam de utilizar as tecnologias e querem fazer parte da sociedade da informação. Estudos como este são necessários no sentido de se desenvolver iniciativas de inclusão digital para os idosos, na intenção de lhes oferecer mais qualidade de vida. Esta investigação permitiu ainda reforçar a ideia de que o uso do computador pode traduzir-se numa alternativa ao nível dos relacionamentos e do entretenimento, oferecendo também ao idoso maior integração social e apoio em vários serviços.

\section{REFERÊNCIAS}

BARDIN, L. (1977). Análise de Conteúdo. Lisboa: Edições 70. 
CHAFFIN, A.J. \& HARLOW, S.D. (2005). Cognitive Learning Applied to Older Adult Learners and Technology. Educational Gerontology, Vol. 31, No. 4, pp. 301329.

CONCI, M. PIANESI, F., ZANCANARO, M. Useful, Social and Enjoyable: Mobile Phone Adoption by Older People, 2009.

CZAJA, S.J. \& LEE, C.C. The impact of the Internet on older adults. In: Charness, N. \& Schaie, K.W. (Eds.). Impact of Technology on Successful Aging, 113-133. New York (EUA): Springer Publishing Company, 2003.

DEMUNTER, C. How skilled are Europeans in using computers and Internet? Statistics in focus, 17/2006. Eurostat. Retirado de http://epp.eurostat.ec.europa.eu/cache/ITY_OFFPUB/KS-NP-06-017/EN/KSNP-06-017-EN.PDF. Acesso em 23 set. 2006.

GONÇALES, M. Experiência do usuário idoso na Internet: o capital técnico e a evolução do conhecimento em TIC's através de redes sociais. Dissertação de mestrado apresentada Universidade Federal do Estado do Rio de Janeiro (UNIRIO), 2011.

HERNÁNDEZ-ENCUENTRA E.; POUSADA M.; GÓMEZ-ZÚÑIGA B. ICT and older people: beyond usability. Educational Gerontology, 35, 226-245, 2009.

INSTITUTO NACIONAL DE ESTATÍSTICA (INE). Lisboa - Portugal. Disponível em:http://censos.ine.pt/ngt_server/attachfileu.jsp?look_parentBoui=131010986\& att_display=n\&att_download=y. Acesso em: 13 abri. 2015.

JONES, B.D. \& BAYEN, U.J. Teaching older adults to use computers: recommendations based on cognitive aging research. Educational Gerontology, 24 (7), pp. 675-689, 1998.

LINH, V. V. Enhancing smartphone's usability for elderly in Finland. HAAGAHLIA University of Applied Sciences disponível em: http://www.theseus.fi/bitstream/handle/10024/69935/Enhancing\%20smartphone $\% 20 \% 20$ usability $\% 20$ for $\% 20$ elderly $\% 20 \mathrm{in} \% 20$ Finland.pdf? sequence $=1$. Acesso em: 08 dez. 2014.

KACHAR, V. (2003). Terceira Idade \& Informática: Aprender revelando potencialidades. São Paulo: Cortez.

MALANOWSKI, N., ÖZCIVELEK, R. \& Cabrera, M. Active Ageing and Independent Living Services: The Role of The Information and Communication Technology. Institute for Prospective Technological Studies. Luxembourg: European Communities, 2008.

MORRIS, M. The effects of an introductory computer course on the attitudes of older adults towards computers. ACM SIGCSE Bulletin, Vol. 24, No. 1, pp. 72-75, 1992.

ORGANIZAÇÃO DAS NAÇÕES UNIDAS. Assembléia mundial sobre envelhecimento: resolução 39/125. Viena, 1982.

PURDIE, N. and BOULTON-LEWIS, G. The Learning needs of older adults. Educational Gerontology. Vol. 29, No. 2, pp. 129-149, 2003.

ROGERS, W.A.; MAYHORN, C. ; FISK, A. Technology in Everyday Life for Older Adults. In Gerontechnology: Research and Practice in Technology and Aging. D. Burdick and S. Kwon (Eds.), pp. 3-17, 2004.

SALES, M.B.; AMARAL, M.A; SENE JUNIOR, I. G.; Sales, A.B.; Tecnologias de Informação e Comunicação via Web: Preferências de uso de um grupo de usuários idosos. Disponível em: http://revistas.pucsp.br/index.php/kairos/article/view/21507/15756. Acesso em: 10 fev. 2015. 
SALES, M. B. (2002). Desenvolvimento de um checklist para a avaliação de acessibilidade da Web para usuários idosos. Dissertação de mestrado em Engenharia de Produção. Curso de Pós-Graduação em Engenharia de Produção Universidade Federal de Santa Catarina, Florianópolis (SC). Disponível em: $<$ http://tede.ufsc.br/teses/PEPS2193-D.pdf $>$. Acesso em: 10 junh. 2014.

SALES, M. B. Modelo multiplicador utilizando a aprendizagem por pares focado do idoso. (138 f.). Tese de doutorado em Engenharia e Gestão do Conhecimento. Curso de Pós-Graduação em Engenharia e Gestão do Conhecimento, Universidade Federal de Santa Catarina, Florianópolis (SC). Disponível em: 20 junho, 2014, de: <http://btd.egc.ufsc.br/wpcontent/uploads/2010/06/Marcia-Barros-de-Sales.pdf>. Acesso em 11 junh. 2007.

SENIORWATCH. Assessment of the Senior Market for ICT Progress and Developments, final report. Disponível em: http://ec.europa.eu/information_society/newsroom/cf/itemdetail.cfm?item_id=42 86. Acesso em 21 jan. 2008.

WASSERMAN, C.; GRANDE, T.; MACHADO, L.; BEHAR, P. Redes sociais: um novo mundo para os idosos. Renote, 10(1). 2012. Disponível em: http://seer.ufrgs.br/renote/article/view/30863. Acesso em 19 junh. 2015. 